\title{
Comparative analysis of long-term outcomes of torasemide and furosemide in heart failure patients in heart failure registries of the European Society of Cardiology
}

\author{
Krzysztof Ozierański ${ }^{1}$, Paweł Balsam ${ }^{1}$, Agnieszka Kapłon-Cieślicka ${ }^{1}$, Agata \\ Tymińska ${ }^{1}$, Robert Kowalik ${ }^{1}$, Marcin Grabowski ${ }^{1}$, Michał Peller ${ }^{1}$, Anna \\ Wancerz ${ }^{1}$, Michał Marchel ${ }^{1}$, Maria G. Crespo-Leiro ${ }^{2}$, Aldo P. Maggioni ${ }^{3,4}$, \\ Jarosław Drożdż ${ }^{5}$ Krzysztof J. Filipiak1, Grzegorz Opolski ${ }^{1}$ \\ ${ }^{1}$ Department of Cardiology, Public Central Teaching Hospital in Warsaw, Medical University of Warsaw, 1 a \\ Banacha St., 02-097 Warsaw, Poland \\ ${ }^{2}$ Unidad de Insuficiencia Cardiaca Avanzada y Trasplante Cardiaco, Hospital Universitario A Coruna, \\ CIBERCV, La Coruna, Spain \\ ${ }^{3}$ ANMCO Research Centre, Florence, Italy \\ 4 EURObservational Research Programme, European Society of Cardiology, Sophia Antipolis, France \\ ${ }^{5}$ Department of Cardiology, Cardiology and Cardiac Surgery, Medical University of Lodz, Lodz, Poland
}

\begin{abstract}
Purpose. Current clinical recommendations do not emphasise superiority of any of diuretics, but available reports are very encouraging and suggest beneficial effects of torasemide. This study aimed to compare the effect of torasemide and furosemide on long-term outcomes and New York Heart Association (NYHA) class change in patients with chronic heart failure (HF).

Methods. Of 2019 patients enrolled in Polish parts of the heart failure registries of the European Society of Cardiology (Pilot and Long-Term), 1440 patients treated with a loop diuretic were included in the analysis. The main analysis was performed on matched cohorts of HF patients treated with furosemide and torasemide using propensity score matching.

Results. Torasemide was associated with a similar primary endpoint (all-cause death; 9.8\% vs. 14.1\%; $p=0.13$ ) occurrence and $23.8 \%$ risk reduction of the secondary endpoint (a composite of all-cause death or hospitalisation for worsening HF; $26.4 \%$ vs. $34.7 \% ; p=0.04)$. Treatment with both torasemide and furosemide was associated with the significantly most frequent occurrence of the primary $(23.8 \%)$ and secondary $(59.2 \%)$ endpoints. In the matched cohort after 12 months, NYHA class was higher in the furosemide group $(p=0.04)$, while furosemide use was associated with a higher risk $(20.0 \%$ vs. $12.9 \%$; $p=0.03$ ) of worsening $\geq 1$ NYHA class. Torasemide use impacted positively upon the primary endpoint occurrence, especially in younger patients (aged $<65$ years) and with dilated cardiomyopathy.

Conclusions. Our findings contribute to the body of research on the optimal diuretic choice. Torasemide may have advantageous influence on NYHA class and long-term outcomes of HF patients, especially younger patients or those with dilated cardiomyopathy, but it needs further investigations in prospective randomised trials.
\end{abstract}

Keywords

Heart failure; Loop diuretic; Furosemide; Torasemide 


\section{Introduction}

Approximately 50\% of heart failure (HF) patients are readmitted to hospital within 6 months due to HF deterioration, which indicates that symptomatic treatment of HF requires significant improvement [1]. HF-related readmissions can be reduced by proper management of fluid retention [2]. As demonstrated by recent European registries, diuretics are prescribed in approximately $83 \%$ of patients with chronic HF at hospital discharge and ambulatory care [3, 4]. Current recommendations do not emphasize the superiority of any of the available diuretics [1]. Furosemide is the most commonly used loop diuretic, yet it is known that as a non-potassiumsparing diuretic (PSD), it activates aldosterone secretion. It was shown in a retrospective analysis of Studies Of Left Ventricular Dysfunction (SOLVD), that it may lead to negative outcomes (HF hospitalization, death from cardiovascular or all-causes) compared to PSD alone or combined therapy [5]. Emerging evidence is encouraging, suggesting a range of beneficial effects of torasemide. Several small studies suggested a potential decrease in mortality and hospitalizations for worsening HF [6, 7]. Further, in TORasemide In Chronic Heart Failure (TORIC) study, torasemide was related with lower mortality and was more efficacious than furosemide in improving New York Heart Association (NYHA) functional class [6]. Additionally, torasemide has been shown to have a favourable effect on the renin-angiotensin-aldosterone system (RAAS) [8]. In patients with chronic HF, torasemide attenuated cardiac fibrosis and left ventricular remodelling $[9,10]$. That being said, given the frequent deteriorations of $\mathrm{HF}$, there is a clear need for further research comparing torasemide with furosemide, both in randomised trials, as well as in real-life patients in an everyday practice.

Our study sought to compare the effect of torasemide and furosemide on long-term outcomes and NYHA functional class change in patients with chronic HF, enrolled in Polish parts of the heart failure registries of the European Society of Cardiology (ESC)-Pilot and Long-Term.

\section{Methods}

\section{Study Design}

The study consisted of the Polish data from two prospective, observational ESC-HF registries-Pilot and Long-Term. The Pilot study, lasting from October 2009 to May 2010, enrolled patients in 136 European cardiology centres (29 from Poland). The Long-Term registry was conducted in 211 centres from 21 European countries, from May 2011 to April 2013. Patients were enrolled on a 1 day per week basis for 12 consecutive months. A list of the participating centres has been previously published $[11,12]$. The surveys were approved by a local ethical review board.

Registries included outpatients and inpatients with chronic, worsening or new-onset HF. The studies enrolled patients who were over 18 years of age, met diagnostic criteria for HF and provided informed written consent. There were no specific exclusion criteria. Investigators gathered data regarding medical history, demographics, clinical status, diagnostic tests result, pharmacotherapy and 1-year observation.

The total daily dose of loop diuretics was assessed for each patient. According to the manufacturer's recommendations, $40 \mathrm{mg}$ of furosemide corresponds with $10 \mathrm{mg}$ of torasemide. In order to unify the doses of loop diuretics for analysis, the following four levels of doses of furosemide were established: dose 1, $\leq 40 \mathrm{mg}$; dose 2,>40-80 mg; dose 3,> 80-120 mg; and dose $4,>120 \mathrm{mg}$, which corresponded with the following doses of torasemide: dose $1, \leq 10 \mathrm{mg}$; dose 2 , $>10-20 \mathrm{mg}$; dose 3,>20-30 mg; and dose 4, > $30 \mathrm{mg}$. A comparison of similar doses was performed by Eshaghian et al. [13]. 


\section{Study Population and Group Selection}

In the registries ESC-HF Pilot and ESC-HF Long-Term, 5118 and 12,440 patients across Europe were enrolled, respectively. The total Polish cohort of the registry consisted of 2019 Caucasian patients, including 1415 inpatients and 604 outpatients. The final analysis included 1440 inpatients who survived and were discharged in a stable condition, as well as ambulatory patients with chronic HF. Among those 1440 patients, 986, 319 and 135 patients had prescribed furosemide, torasemide or both furosemide and torasemide, respectively. Death (analysed only in hospitalised patients) and lack of loop diuretic were the reasons for exclusion in 579 subjects. Figure 1 shows the flow chart of patient enrollment in the study. Data on 1-year survival, 1-year survival or readmission for decompensated HF, and NYHA functional class change were available for 1381 (95.9\%), $1255(87.2 \%)$ and 1162 (80.7\%) of the 1440 patients, respectively.

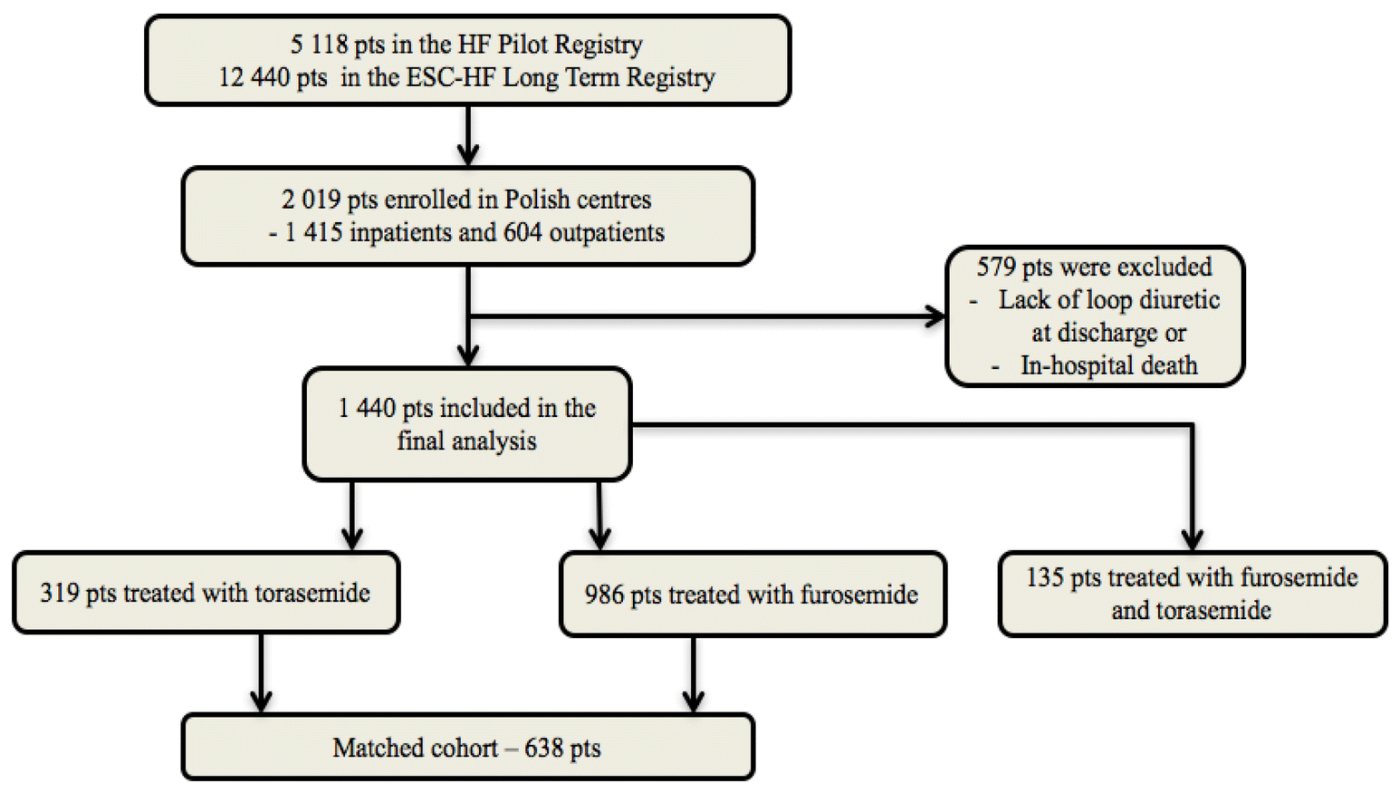

Fig. 1 Flow chart of patient enrollment in the study

\section{Comparative Analysis of Patients Treated with Loop Diuretics}

Investigators assessed the frequency of usage of loop diuretics and baseline characteristics (discharge data in case of hospitalised patients) of patients treated with furosemide and torasemide. The main analysis was performed on matched groups of HF patients treated with furosemide and torasemide using propensity score matching. Matched cohorts were compared with regard to the occurrence of primary endpoint (all-cause death at 1 year), secondary endpoint (a composite of allcause death or hospitalisation for worsening HF at 1 year) and changes in NYHA functional class from baseline to the end of 12-month follow-up. Additionally, 1-year outcomes and NYHA functional class change were also measured for patients treated with both furosemide and torasemide. 


\section{Statistical Analysis}

For the comparison of the groups' characteristics, the Fisher exact test and Mann-Whitney $U$ test were performed for categorical and continuous variables, respectively. Propensity scores for treatment with torasemide or furosemide were estimated for each patient with logistic regression using four clinically relevant baseline variables (age, gender, NYHA functional class, diuretic dose), which were consistent with variables used by investigators of the TORIC study [6]. The propensity score is the propensity from 0 to 1 to receive a treatment. It is used in observational studies to attempt to adjust for potential selection bias, confounding and differences between treatment groups [14, 15]. Matching was 1:1 and without replacement. Each patient with torasemide was matched to the closest patient with furosemide. This yielded 319 patients in each group. Kaplan-Meier curves were plotted for the primary and the secondary endpoints. Interactions between torasemide or furosemide use and all baseline variables in the matched cohort were estimated by Cox regression analysis and displayed in a forest plot. All tests were two tailed, and a $p$ value less than 0.05 was considered significant. Statistical analyses were performed using SPSS software, version 22 (IBM SPSS Statistics 22, New York, USA).

\section{Results}

\section{Baseline Characteristics}

Before matching, there were significant differences between treatment groups. Patients in the furosemide group had a worse clinical condition manifested by lower ejection fraction, higher resting heart rate, lower systolic blood pressure, higher serum creatinine level and lower haemoglobin concentration, and therefore, they required a higher diuretic dose than patients in the torasemide group. Moreover, they more frequently received oral anticoagulation and less frequently beta-blockers than patients treated with torasemide. After matching, the furosemide and torasemide groups differed only in a higher incidence of stroke history in the torasemide group. Baseline characteristics of both groups, regarding medical history, clinical status and pharmacotherapy, are presented in Table 1. 
Table 1 Baseline characteristics of the overall and matched cohorts of patients in the furosemide and torasemide groups

\begin{tabular}{|c|c|c|c|c|c|c|c|}
\hline \multirow{2}{*}{ Variable } & \multicolumn{4}{|l|}{ Overall cohort } & \multicolumn{3}{|l|}{ Matched cohort } \\
\hline & $\begin{array}{l}\text { Furosemide and torasemide } \\
(n=135)\end{array}$ & $\begin{array}{l}\text { Furosemide group } \\
(n=986)\end{array}$ & $\begin{array}{l}\text { Torasemide group } \\
(n=319)\end{array}$ & $p$ value & $\begin{array}{l}\text { Furosemide group } \\
(n=319)\end{array}$ & $\begin{array}{l}\text { Torasemide group } \\
(n=319)\end{array}$ & $p$ value \\
\hline \multicolumn{8}{|l|}{ Demographics } \\
\hline Age, years & $66(58-77) ; n=135$ & $67(58-77) ; n=986$ & $67(58-77) ; n=319$ & $0.89^{*}$ and $0.81 * *$ & $68(59-77) ; n=319$ & $67(58-77) ; n=319$ & 0.60 \\
\hline Male & $72.6 \% ; 98 / 135$ & $70.7 \% ; 697 / 986$ & $69.6 \% ; 222 / 319$ & $0.72 *$ and $0.86^{* *}$ & $69.6 \% ; 222 / 319$ & $69.6 \% ; 222 / 319$ & 1.00 \\
\hline BMI, $\mathrm{kg} / \mathrm{m}^{2}$ & $28.0(25.0-31.3) ; n=135$ & $28.0(24.9-31.0) ; n=981$ & $27.0(25.0-32.0) ; n=319$ & $0.71^{*}$ and $0.15^{* *}$ & $28.0(25.0-31.7) ; n=319$ & $27.0(25.0-32.0) ; n=319$ & 0.71 \\
\hline \multicolumn{8}{|c|}{$\mathrm{c}$} \\
\hline LVEF, \% & $29(20-40) ; n=131$ & $32(24-45) ; n=913$ & $35(25-50) ; n=309$ & $0.01 *$ and $<0.001^{* *}$ & $35(25-46) ; n=299$ & $35(25-50) ; n=309$ & 0.30 \\
\hline Diuretic dose $\mathrm{e}^{* * *}$ & $3(2-4) ; n=135$ & $1(1-2) ; n=986$ & $1(1-1) ; n=319$ & $\begin{array}{l}<0.0001^{*} \text { and } \\
<0.0001^{*}\end{array}$ & $1(1-1) ; n=319$ & $1(1-1) ; n=319$ & 0.19 \\
\hline Ischaemic heart disease & $43.7 \% ; 59 / 135$ & $53.7 \% ; 529 / 986$ & $52.2 \% ; 166 / 318$ & $0.65^{*}$ and $0.06^{* *}$ & $57.4 \% ; 183 / 319$ & $52.2 \% ; 166 / 318$ & 0.20 \\
\hline Dilated cardiomyopathy & $28.9 \% ; 39 / 135$ & $18.5 \% ; 182 / 986$ & $19.1 \% ; 61 / 319$ & $0.80^{*}$ and $0.02^{* *}$ & $17.2 \% ; 55 / 319$ & $19.1 \% ; 61 / 319$ & 0.61 \\
\hline Valve disease & $15.6 \% ; 21 / 135$ & $12.1 \% ; 119 / 986$ & $11.6 \% ; 37 / 319$ & $0.69^{*}$ and $0.51^{* *}$ & $11.6 \% ; 35 / 319$ & $11.6 \% ; 37 / 319$ & 0.90 \\
\hline \multicolumn{8}{|l|}{ Medical history } \\
\hline $\mathrm{AF}$ & $54.1 \% ; 73 / 135$ & $47.2 \% ; 464 / 984$ & $41.4 \% ; 132 / 319$ & $0.08^{*}$ and $0.75^{* *}$ & $44.5 \% ; 142 / 319$ & $41.4 \% ; 132 / 319$ & 0.47 \\
\hline CAD & $54.1 \% ; 73 / 135$ & $51.9 \% ; 511 / 985$ & $55.8 \% ; 178 / 319$ & $0.25^{*}$ and $0.33^{* *}$ & $54.2 \% ; 173 / 319$ & $55.8 \% ; 178 / 319$ & 0.75 \\
\hline History of PCI or CABG & $40.1 \% ; 54 / 135$ & $38.1 \% ; 375 / 985$ & $38.6 \% ; 123 / 319$ & $0.90^{*}$ and $0.51^{* *}$ & $40.1 \% ; 128 / 319$ & $38.6 \% ; 123 / 319$ & 0.75 \\
\hline Hypertension & $65.9 \% ; 89 / 135$ & $61.3 \% ; 603 / 984$ & $67.0 \% ; 213 / 318$ & $0.07 *$ and $0.09^{* *}$ & $63.8 \% ; 203 / 318$ & $67.0 \% ; 213 / 318$ & 0.45 \\
\hline $\mathrm{PAD}$ & $12.6 \% ; 17 / 135$ & $13.2 \% ; 130 / 986$ & $11.0 \% ; 35 / 317$ & $0.33^{*}$ and $0.52 * *$ & $15.0 \% ; 48 / 319$ & $11.0 \% ; 35 / 317$ & 0.16 \\
\hline Diabetes & $40.7 \% ; 55 / 135$ & $36.6 \% ; 361 / 986$ & $30.7 \% ; 98 / 319$ & $0.06^{*}$ and $0.85^{* *}$ & $36.1 \% ; 115 / 319$ & $30.7 \% ; 98 / 319$ & 0.18 \\
\hline CKD & $37.8 \% ; 51 / 135$ & $20.8 \% ; 205 / 984$ & $21.0 \% ; 67 / 319$ & $0.94 *$ and $<0.001 * *$ & $19.1 \% ; 61 / 319$ & $21.0 \% ; 67 / 319$ & 0.62 \\
\hline COPD & $24.4 \% ; 33 / 135$ & $20.0 \% ; 197 / 985$ & $15.7 \% ; 50 / 319$ & $0.10^{*}$ and $0.89^{* *}$ & $20.4 \% ; 65 / 319$ & $15.7 \% ; 50 / 319$ & 0.15 \\
\hline Stroke & $11.9 \% ; 16 / 135$ & $10.6 \% ; 104 / 984$ & $12.9 \% ; 41 / 319$ & $0.26^{*}$ and $0.37^{* *}$ & $7.2 \% ; 23 / 319$ & $12.9 \% ; 41 / 319$ & 0.02 \\
\hline Pacemaker & $6.7 \% ; 9 / 135$ & $7.6 \% ; 75 / 986$ & $5.3 \% ; 17 / 319$ & $0.21 *$ and $0.32 * *$ & $7.8 \% ; 25 / 319$ & $5.3 \% ; 17 / 319$ & 0.26 \\
\hline ICD & $22.2 \% ; 30 / 135$ & $17.3 \% ; 270 / 985$ & $14.4 \% ; 46 / 319$ & $0.19 *$ and $0.57^{* *}$ & $15.7 \% ; 50 / 319$ & $14.4 \% ; 46 / 319$ & 0.65 \\
\hline CRT & $8.1 \% ; 11 / 135$ & $6.5 \% ; 64 / 985$ & $6.6 \% ; 21 / 319$ & $1.00^{*}$ and $0.55^{* *}$ & $6.6 \% ; 21 / 319$ & $6.5 \% ; 64 / 985$ & 0.92 \\
\hline Smoking $^{\dagger}$ & $55.6 \% ; 75 / 135$ & $58.1 \% ; 561 / 966$ & $60.5 \% ; 193 / 319$ & $0.47 *$ and $0.94 * *$ & $56.4 \% ; 177 / 314$ & $60.5 \% ; 193 / 319$ & 0.30 \\
\hline \multicolumn{8}{|l|}{ Clinical status } \\
\hline NYHA class & $3(2-3) ; n=134$ & $2(2-3) ; n=983$ & $2(2-3) ; n=319$ & $0.79 *$ and $<0.001 * *$ & $2(2-3) ; n=319$ & $2(2-3) ; n=319$ & 0.26 \\
\hline $\mathrm{SBP}, \mathrm{mmHg}$ & $120(100-130) ; n=135$ & $125(110-140) ; n=984$ & $130(115-140) ; n=319$ & $0.049^{*}$ and $<0.001^{* *}$ & $126(110-140) ; n=319$ & $130(115-140) ; n=319$ & 0.25 \\
\hline DBP, mmHg & $70(65-80) ; n=135$ & $80(70-81) ; n=983$ & $80(70-86) ; n=319$ & $0.13^{*}$ and $0.002 * *$ & $80(70-80) ; n=319$ & $80(70-86) ; n=319$ & 0.23 \\
\hline Heart rate, bpm & $80(70-100) ; n=135$ & $80(70-96) ; n=983$ & $75(66-90) ; n=319$ & $0.004^{*}$ and $0.049^{* *}$ & $80(68-95) ; n=318$ & $75(66-90) ; n=319$ & 0.17 \\
\hline
\end{tabular}


Table 1 Baseline characteristics of the overall and matched cohorts of patients in the furosemide and torasemide groups

\begin{tabular}{|c|c|c|c|c|c|c|c|}
\hline \multirow{2}{*}{ Variable } & \multicolumn{4}{|l|}{ Overall cohort } & \multicolumn{3}{|l|}{ Matched cohort } \\
\hline & $\begin{array}{l}\text { Furosemide and torasemide } \\
(n=135)\end{array}$ & $\begin{array}{l}\text { Furosemide group } \\
(n=986)\end{array}$ & $\begin{array}{l}\text { Torasemide group } \\
(n=319)\end{array}$ & $p$ value & $\begin{array}{l}\text { Furosemide group } \\
(n=319)\end{array}$ & $\begin{array}{l}\text { Torasemide group } \\
(n=319)\end{array}$ & $p$ value \\
\hline Serum sodium, mmol/1 & $138(135-141) ; n=125$ & $139(136-141) ; n=921$ & $139(137-141) ; n=300$ & $0.20 *$ and $0.04 * *$ & $139(136-141) ; n=303$ & $139(137-141) ; n=300$ & 0.45 \\
\hline Serum potassium, $\mathrm{mmol} / \mathrm{l}$ & $4.5(4.0-4.8) ; n=124$ & $4.4(4.1-4.8) ; n=923$ & $4.4(4.1-4.8) ; n=305$ & $0.74 *$ and $0.99 * *$ & $4.43(4.1-4.8) ; n=305$ & $4.41(4.1-4.8) ; n=305$ & 0.98 \\
\hline Serum creatinine, mg/dl & $1.36(1.09-1.91) ; n=125$ & $1.16(0.93-1.54) ; n=914$ & $1.10(0.88-1.34) ; n=306$ & $0.001^{*}$ and $0.31^{* *}$ & $1.11(0.94-1.45) n=300$ & $1.10(0.88-1.34) ; n=306$ & 0.15 \\
\hline Haemoglobin, g/dl & $13.3(12.0-14.5) ; n=122$ & $13.3(12.0-14.5) ; n=904$ & $13.7(12.2-14.8) ; n=297$ & $0.03^{*}$ and $0.08^{* *}$ & $13.6(12.2-14.7) ; n=303$ & $13.7(12.2-14.8) ; n=297$ & 0.64 \\
\hline \multicolumn{8}{|l|}{ Pharmacotherapy } \\
\hline ACEIs & $74.1 \% ; 100 / 135$ & $80.5 \% ; 794 / 986$ & $80.9 \% ; 258 / 319$ & $0.94 *$ and $0.19^{* *}$ & $80.3 \% ; 256 / 319$ & $80.9 \% ; 258 / 319$ & 0.92 \\
\hline $\mathrm{ARBs}$ & $11.1 \% ; 15 / 135$ & $12.9 \% ; 127 / 985$ & $13.2 \% ; 42 / 319$ & $0.92 *$ and $0.69 * *$ & $14.7 \% ; 47 / 319$ & $13.2 \% ; 42 / 319$ & 0.65 \\
\hline Beta-blockers & $88.1 \% ; 119 / 135$ & $91.4 \% ; 901 / 986$ & $95.3 \% ; 304 / 319$ & $0.02 *$ and $0.02 * *$ & $94.0 \% ; 300 / 319$ & $95.3 \% ; 304 / 319$ & 0.60 \\
\hline Aldosterone antagonists & $77.8 \% ; 105 / 135$ & $70.2 \% ; 692 / 986$ & $70.2 \% ; 224 / 319$ & $1.00^{*}$ and $0.15^{* *}$ & $68.7 \% ; 219 / 319$ & $70.2 \% ; 224 / 319$ & 0.73 \\
\hline $\mathrm{CCBs}$ & $8.1 \% ; 11 / 135$ & $12.0 \% ; 118 / 986$ & $13.5 \% ; 43 / 319$ & $0.49^{*}$ and $0.51^{* *}$ & $16.0 \% ; 51 / 319$ & $13.5 \% ; 43 / 319$ & 0.43 \\
\hline Statins & $57.0 \% ; 77 / 135$ & $66.6 \% ; 657 / 986$ & $68.3 \% ; 218 / 319$ & $0.58^{*}$ and $0.14^{* *}$ & $66.5 \% ; 212 / 319$ & $68.3 \% ; 218 / 319$ & 0.67 \\
\hline Amiodarone & $17.0 \% ; 23 / 135$ & $10.5 \% ; 104 / 986$ & $11.3 \% ; 36 / 319$ & $0.76^{*}$ and $0.06^{* *}$ & $7.8 \% ; 25 / 319$ & $11.3 \% ; 36 / 319$ & 0.18 \\
\hline Other antiarrhythmics & $6.7 \% ; 9 / 135$ & $6.0 \% ; 59 / 986$ & $5.6 \% ; 18 / 319$ & $0.89^{*}$ and $0.89^{* *}$ & $5.3 \% ; 17 / 319$ & $5.6 \% ; 18 / 319$ & 1.00 \\
\hline Digoxin & $34.1 \% ; 46 / 135$ & $30.0 \% ; 296 / 986$ & $26.0 \% ; 83 / 319$ & $0.18^{*}$ and $0.92^{* *}$ & $25.7 \% ; 82 / 319$ & $26.0 \% ; 83 / 319$ & 1.00 \\
\hline $\mathrm{OAC}$ & $57.8 \% ; 78 / 135$ & $47.3 \% ; 466 / 985$ & $38.6 \% ; 123 / 319$ & $0.01^{*}$ and $0.001^{* *}$ & $43.9 \% ; 140 / 319$ & $38.6 \% ; 123 / 319$ & 0.20 \\
\hline Antiplatelets & $51.1 \% ; 69 / 135$ & $58.5 \% ; 577 / 986$ & $62.7 \% ; 200 / 319$ & $0.19^{*}$ and $0.51^{* *}$ & $63.0 \% ; 201 / 319$ & $62.7 \% ; 200 / 319$ & 1.00 \\
\hline
\end{tabular}

Values in italics indicate $p$ values $<0.05$

$A C E I s$ angiotensin-converting enzyme inhibitors, $A F$ atrial fibrillation, $A R B s$ angiotensin receptor blockers, $B M I$ body mass index, $C A B G$ coronary artery bypass grafting, $C A D$ coronary artery disease, $C C B$. calcium channel blockers, $C K D$ chronic kidney disease, $C O P D$ chronic obstructive pulmonary disease, $C R T$ cardiac resynchronization therapy, $D B P$ diastolic blood pressure, $H F$ heart failure, $I C D$ implantable cardioverter defibrillator, $L V E F$ left ventricular ejection fraction, NYHA New York Heart Association, $O A C$ oral anticoagulant, $P A D$ peripheral artery disease, $P C I$ percutaneous coronary intervention, $S B P$ systolic blood pressure

$* p$ value for comparison of torasemide versus furosemide groups

$* * p$ value for any trend between groups

****Diuretic dose was established as levels from 1 to 4 . A detailed explanation is mentioned in the "Methods" section

${ }^{\dagger}$ Current or former 
Of the 319 patients treated with torasemide, 25 patients $(7.8 \%)$ received additional diuretics (hydrochlorothiazide, chlorthalidone or indapamide), while in the furosemide group (consisting of 986 patients), 89 patients $(9.0 \%)$ were treated with additional diuretics.

In the matched cohort, the doses of the loop diuretics were as follows: dose 1 ( 272 patients of the torasemide group vs. 259 patients of the furosemide group), dose 2 (32 vs. 44, respectively), dose 3 (6 vs. 8, respectively) and dose 4 ( 9 vs. 8 , respectively).

\section{Primary and Secondary Endpoints}

\section{Overall Cohort}

The primary endpoint in the unmatched cohorts was reached in $13.1 \%, 9.8 \%$ and $23.8 \%$ ( $p$ value of 0.01 for any trend) of patients in the furosemide, torasemide and both furosemide and torasemide groups, respectively. The secondary endpoint occurred in $37.2 \%, 26.4 \%$ and $59.2 \%$ ( $p$ value $<0.0001$ for any trend) of patients in the furosemide, torasemide and both furosemide and torasemide groups, respectively.

\section{Matched Cohort}

In the matched cohort, the torasemide group was found to have a $30.2 \%$ reduction in the risk of death compared to the furosemide group, but it was not statistically significant $(p=0.13$ ) (Table $2)$. A total of $30(9.8 \%)$ patients in the torasemide group and $43(14.1 \%)$ patients in the furosemide group died during the study. In the matched cohort, in the torasemide-treated patients, there was a $23.8 \%$ risk reduction of the secondary endpoint $(p=0.04)$. During the 1 -year follow-up, death or hospitalisation for worsening HF occurred in a total of 74 (26.4\%) patients in the torasemide group and $95(34.7 \%)$ patients in the furosemide group. Kaplan-Meier curves for the primary and secondary endpoints are plotted in Fig. 2.

Table 2 Incidence of the primary and secondary endpoints, and NYHA functional class at 1 year in patients who received torasemide, furosemide or both furosemide and torasemide (in the matched and not matched cohorts)

\begin{tabular}{|c|c|c|c|c|c|c|}
\hline & \multicolumn{4}{|l|}{ Overall cohort } & \multicolumn{2}{|l|}{ Matched cohort } \\
\hline & $\begin{array}{l}\text { Furosemide and } \\
\text { torasemide group } \\
(n=135)\end{array}$ & $\begin{array}{l}\text { Furosemide } \\
\text { group }(n=986)\end{array}$ & $\begin{array}{l}\text { Torasemide group } \\
(n=319)\end{array}$ & $p$ value* & $\begin{array}{l}\text { Furosemide group } \\
(n=319)\end{array}$ & $\begin{array}{l}p \\
\text { value** }\end{array}$ \\
\hline Death & $23.8 \% ; 31 / 130$ & $13.1 \% ; 124 / 946$ & $9.8 \% ; 30 / 305$ & 0.01 & $14.1 \% ; 43 / 305$ & 0.13 \\
\hline $\begin{array}{l}\text { Death or } \\
\text { hospitalisation }\end{array}$ & $59.2 \% ; 74 / 125$ & $37.2 \% ; 316 / 850$ & $26.4 \% ; 74 / 280$ & $<0.0001$ & $34.7 \% ; 95 / 274$ & 0.04 \\
\hline $\begin{array}{l}\text { NYHA class at } \\
12 \text { months }\end{array}$ & $3(2-3) ; n=101$ & $2(2-3) ; n=886$ & $2(2-2) ; n=262$ & 0.001 & $2(2-3) ; n=254$ & 0.04 \\
\hline
\end{tabular}

Values in italics indicate $p$ values $<0.05$

$* p$ value for any trend between groups in the not matched cohorts

** $p$ value for comparison of torasemide versus furosemide groups in the matched cohorts 

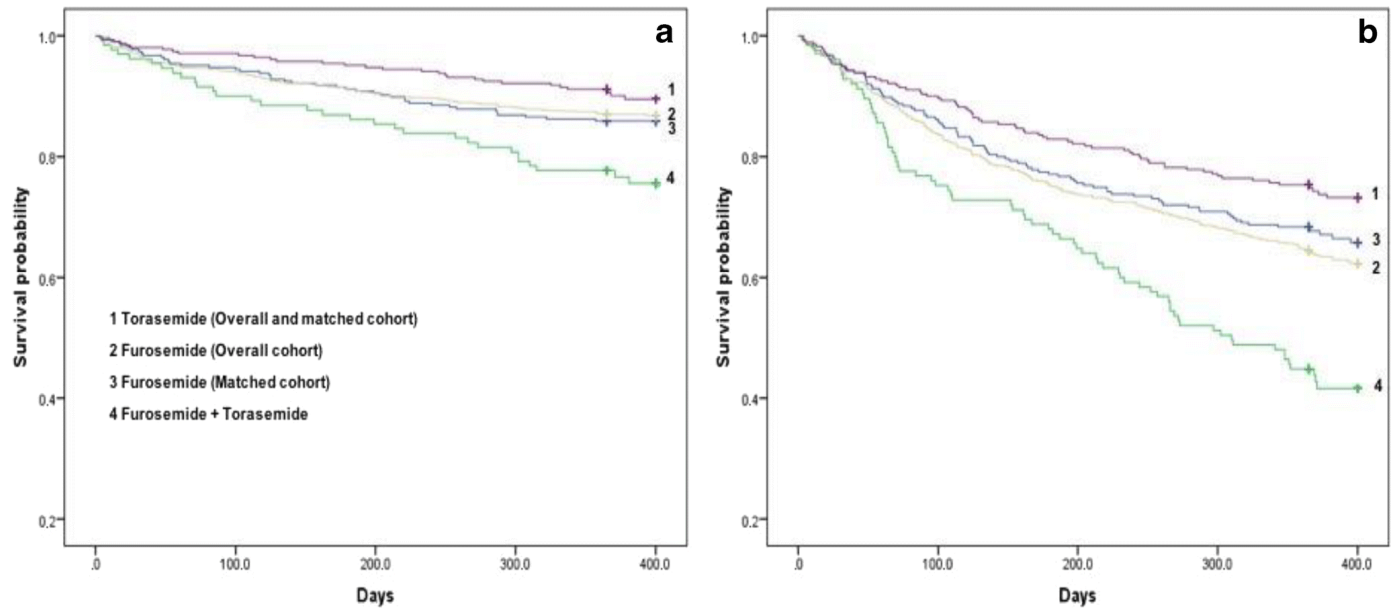

Fig. 2 Kaplan-Meier curves for the primary (a) and secondary (b) endpoints in matched cohorts treated with furosemide or torasemide, and both furosemide and torasemide

Treatment with both torasemide and furosemide was associated with the most frequent occurrence of the primary $(23.8 \%)$ and secondary (59.2\%) endpoints (Table 2). The results were statistically significant.

\section{Change in NYHA Class}

\section{Overall Cohort}

In the unmatched cohorts, the median NYHA class at 12 months was as follows: $2(2-3), 2$ (22 ) and $3(2-3)$ ( $p$ value of 0.001 for any trend) of patients in the furosemide, torasemide and both furosemide and torasemide groups, respectively.

\section{Matched Cohort}

At baseline, patients in the torasemide and furosemide groups did not differ in NYHA functional class, while after 12 months in the furosemide group, NYHA functional class was significantly higher $(p=0.04)$. Improvement of $\geq 1$ NYHA functional class was greater in the torasemide group (67 patients, 25.6\%) than in the furosemide group (53 patients, 20.9\%) $(p=0.21)$. Furthermore, furosemide use was associated with a significantly higher risk $(20.0 \%$ vs. $12.9 \%, p=0.03$ ) of worsening $\geq 1$ NYHA functional class. Figure 3 shows the change in NYHA functional class. 


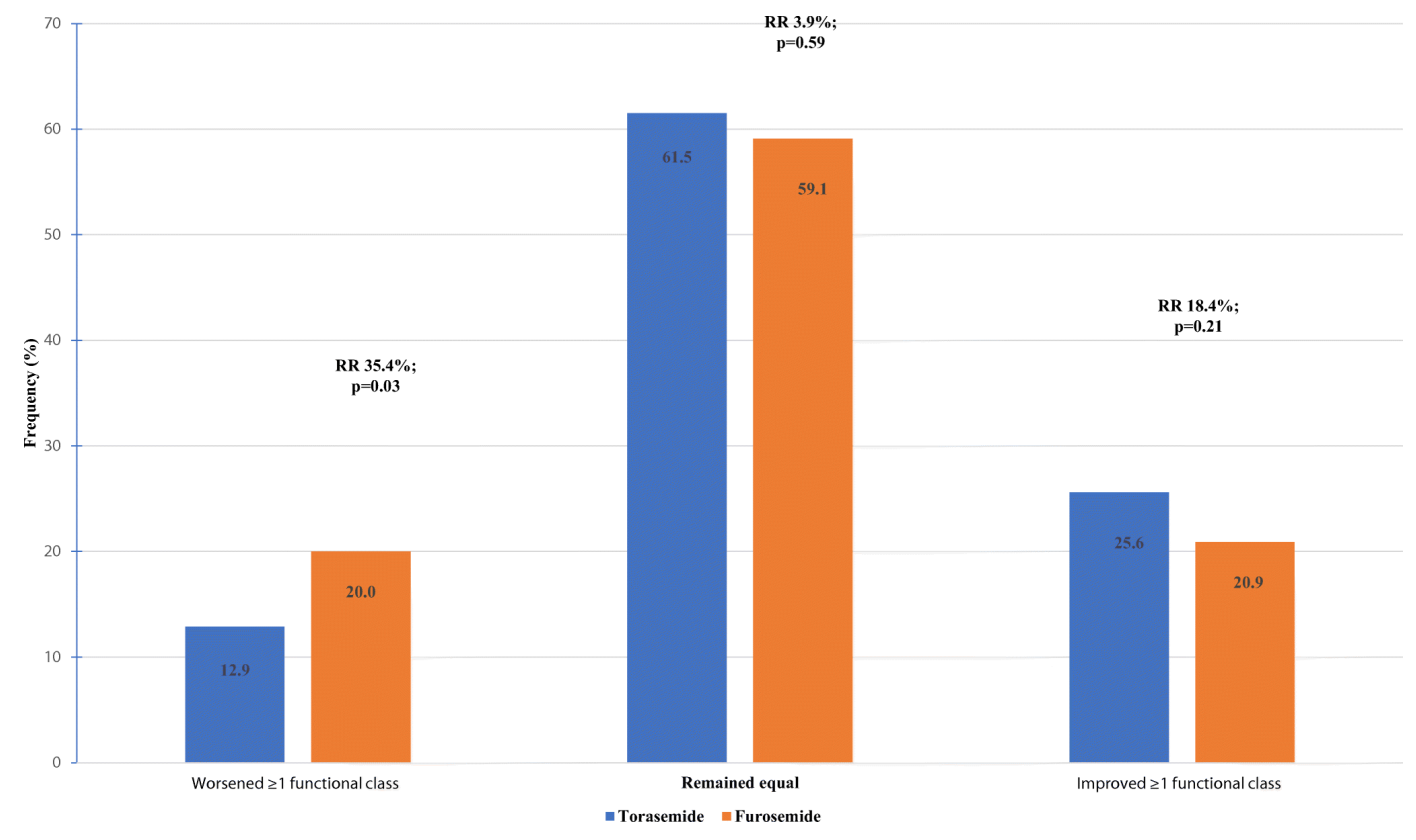

Fig. 3 Changes in New York Heart Association (NYHA) functional class from baseline to the end of 12-month follow-up in the matched cohort

\section{Loop Diuretics in Subgroups of Patients with HF}

Interactions of the use of loop diuretics in the matched cohort for clinically relevant baseline variables are presented in Fig. $4 \mathrm{a}, \mathrm{b}$ (for the primary and secondary endpoints, respectively). In patients treated with torasemide, a positive impact on the primary endpoint occurrence was observed in younger patients (aged $<65$ years), with dilated cardiomyopathy, using antiplatelets or digitalis. A lower risk of death or hospitalisation for HF worsening was observed in patients who were treated with torasemide and who were 65-75 years of age, treated with angiotensinconverting enzyme inhibitors (ACEIs)/angiotensin receptor blocker (ARB), statins or antiplatelets. In patients treated with a low dose ( $\leq 40 \mathrm{mg}$ of furosemide or $\leq 10 \mathrm{mg}$ of torasemide) of a loop diuretic, patients using torasemide were less likely to reach the secondary endpoint. 


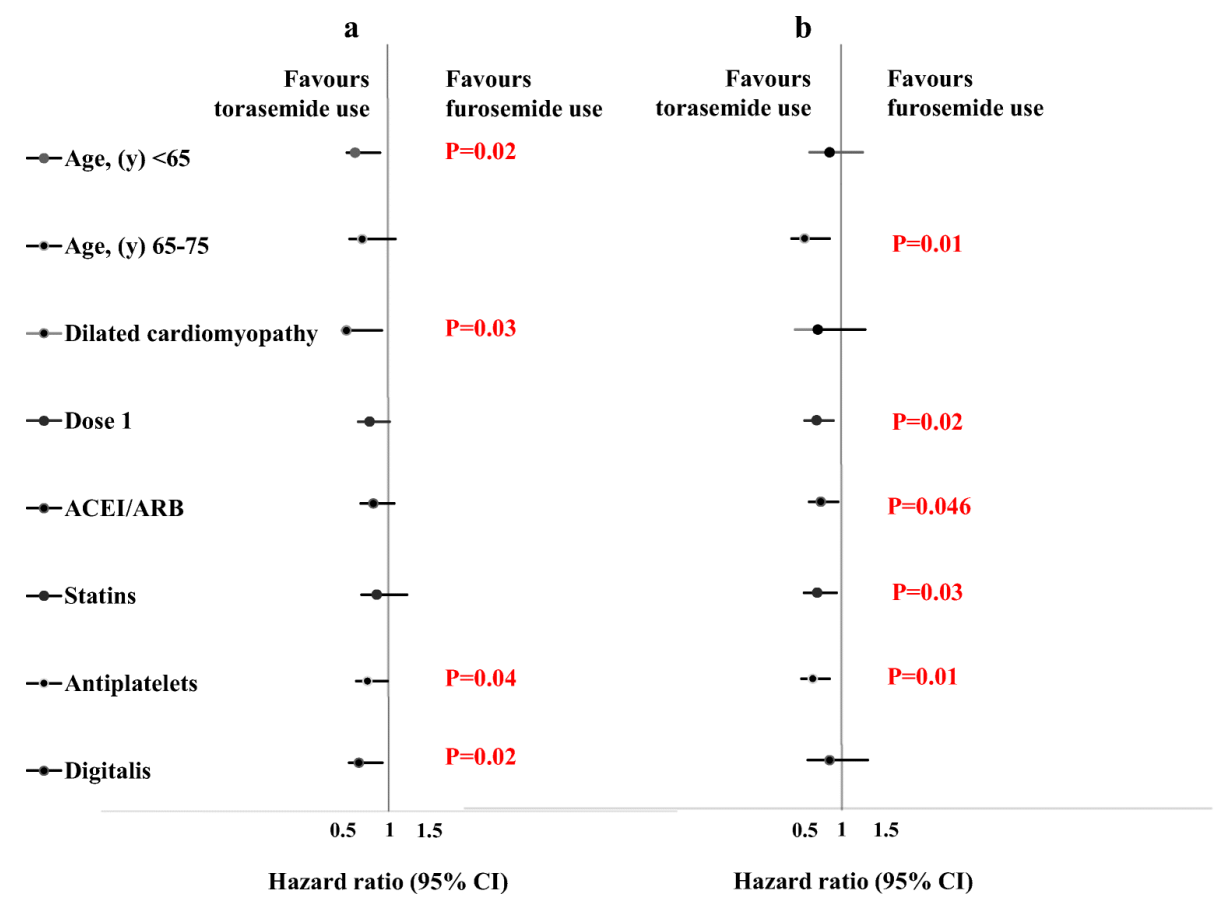

Fig. 4 All-cause mortality (a) and mortality or hospitalization for worsening HF (b) at one-year for patients treated with torasemide vs treated with furosemide in the matched cohort (part 1). ACE-I - angiotensin-converting-enzyme inhibitors, ARB - angiotensin receptor blockers, BB - beta-blockers. Red bolded text indicates $p$-values $<0.05$. Diuretic dose was established as levels from 1 to 4. Detailed explanation is placed in the Methods" section

\section{Discussion}

The results of this observational cohort study showed that in real-life patients treated with torasemide, in comparison with furosemide, there were no significant differences in terms of the primary endpoint. However, in the torasemide-treated group, death or HF hospitalisation less frequently occurred. It seems that patients in the torasemide group were also more likely to have less HF symptoms (manifested by NYHA functional class change), thus confirming the results of previous studies $[6,7,16,17]$. Nevertheless, the worse 1-year outcomes occurred in the group treated with both furosemide and torasemide.

There is currently no consensus as to which of the loop diuretics (furosemide or torasemide) should be the preferred choice in HF patients. Torasemide appears to be a drug with greater potential, but so far, there has been insufficient research into its effects in HF therapy. The subanalysis of the Acute Study of Clinical Effectiveness of Nesiritide in Decompensated Heart Failure (ASCEND-HF) trial demonstrated that there was a significant regional variation in the use of loop diuretics. Specifically, torasemide is used less frequently than furosemide in the USA (11.4\%), China (9.4\%) and Poland (6.3\%) [16]. In our analysis, the most commonly used loop diuretic among Polish patients participating in both ESC-HF registries was furosemide (75.6\% vs. $24.4 \%$ patients treated with torasemide). These results suggest that physicians still have a stronger preference to prescribe furosemide than torasemide. 
Loop diuretics are the most efficacious drugs in relieving clinical signs and symptoms of HF [18]. However, there is a near consensus that diuretics do not improve the prognosis of HF patients and may be associated with progression of HF due their impact on RAAS activation and harmful effect on electrolyte concentrations $[19,20]$. Even so, available data suggests that torasemide may offer additional advantages regarding HF hospitalizations, functional improvement, quality of life and even mortality, over furosemide and other diuretics [5, 6, 7].

In a randomised, open-label trial in 234 patients with chronic HF, Murray et al. [7] showed a significant reduction in hospitalization rates for $\mathrm{HF}$ and cardiovascular causes in torasemidetreated patients, as compared to furosemide. In the TORIC study, torasemide treatment was associated with a significantly lower total and cardiac mortality [6]. In addition, in some studies in torasemide-treated patients, compared to treatment with furosemide or other diuretics, there was a significantly greater improvement in NYHA functional class [6, 17, 21]. Based on the available results of the previous and current studies, no conclusions can be drawn regarding the effect of diuretics on mortality. What is more, more facts speak against the effectiveness of diuretics in improving the primary endpoint. However, it is expected that further data will be provided by the recently registered ToRsemide compArisoN With furoSemide FORManagement of Heart Failure (TRANSFORM-HF) study, which will enroll 6000 patients hospitalised for HF in the USA, and which aims to compare the effects of treatment strategy based on torasemide versus furosemide on clinical outcomes over 12 months (ClinicalTrials.gov Identifier: NCT03296813).

It remains unclear which populations of HF patients may especially benefit from treatment with torasemide. An analysis of the matched cohort revealed that in terms of the primary endpoint treatment with torasemide would especially benefit younger patients (aged $<65$ years), with dilated cardiomyopathy and treated with antiplatelets or digitalis (Fig. 4), while the secondary endpoint was reduced in patients treated with torasemide and who required a low dose of a loop diuretic ( $\leq 40 \mathrm{mg}$ of furosemide or $\leq 10 \mathrm{mg}$ of torasemide), were treated with ACEI or ARB, antiplatelets or statins (Fig. 4b). These results are consistent with the study of Han et al. [22], showing that torasemide is advantageous in improving cardiac function by reducing arrhythmia and chronic HF in patients with dilated cardiomyopathy, as compared to furosemide. It has also been shown that HF patients not receiving ACEI/ARB or beta-blockers, a core treatment of HF, have a higher mortality risk [23, 24]. This effect is reflected especially with increasing doses of a loop diuretic, probably due to the RAAS activation by diuretics [23, 25].

In our study, the highest risk of the primary and secondary outcomes was observed in patients treated with both furosemide and torasemide, but those patient groups were not matched. It is unclear whether a worse long-term prognosis, associated with the simultaneous use of both loop diuretics, depends on the generally worse condition of those patients or whether it can be ascribed to the direct effect of application of the two diuretics. It has been shown that the risk of mortality is dose dependent and increases with the diuretic dose [13, 23]. Notably, the threshold value of $50 \mathrm{mg}$ of furosemide daily was identified as the strongest predictor of death within 3 years [23]. A similar threshold dose for torasemide has not been investigated.

Torasemide has smaller inter- and intraindividual variations in bioavailability and longer action, reduces body weight and decreases the number of micturition at $3 \mathrm{~h}, 6 \mathrm{~h}$ and $12 \mathrm{~h}$ after diuretic intake and the urgency to urinate $[26,27]$. Consequently, torasemide has more predictable pharmacokinetics/pharmacodynamics, weaker influence on electrolyte concentrations and, therefore, an improved tolerability compared to furosemide [28]. Vargo et al. [26] showed that in contrast to furosemide, the rate of absorption of orally administered torasemide was not affected in patients with HF. 
Separately, torasemide, beyond its pure diuretic effect, might also provide additional benefits in patients with HF. Diuretics, especially furosemide, provoke the activation of RAAS [29]. Contrastingly, torasemide combines the effects of diuretics, but also those of spironolactone (manifested by the RAAS blockade) [8]. Therefore, torasemide might attenuate myocardial remodelling and cardiac fibrosis [10]. Through an inhibition of aldosterone receptor, torasemide may also promote lesser potassium excretion than furosemide [6]. The antialdosterone action of torasemide may explain its ability to improve prognosis in HF patients. The TORasemide oN hemodynAmic and neurohormonal stress, and carDiac remOdelling in heart failure (TORNADO, NCT01942109), is an ongoing randomised clinical trial, may provide insight in this as it aims to assess the favourable effects of torasemide on biochemical and clinical parameters, and its effectiveness versus furosemide in improving cardiac remodelling and haemodynamic and neurohormonal stress in patients with HF [30].

So far, two expert groups, drawing on the available clinical reports and economic advantages, recommended consideration of torasemide use over furosemide in HF patients [31, 32]. It seems that our study supports previous reports demonstrating that treatment with torasemide might translate into improvement of NYHA functional class, quality of life and better prognosis of patients with HF, compared to furosemide, but it is just an observational study. Particular groups of patients which may possibly benefit from torasemide treatment are younger patients and those with dilated cardiomyopathy. However, there is a need for further randomised clinical trials to clarify this possible positive effect of torasemide. On the other hand, patients who were treated with both torasemide and furosemide had a worse prognosis, most likely due to a worse clinical condition at baseline.

\section{Limitations of the Study}

A limitation of the study was an insufficient number of study patients to perform a propensity score matching for all clinically relevant variables. For the same reason, we were not able to compare patients treated with both furosemide and torasemide (135 patients) with patients treated with torasemide or furosemide alone. To unify the doses of loop diuretics for analysis, the authors had to establish the four levels of doses, but it was consistent with a previously performed analysis [13]. The main advantage of the registries is that they include real-world patients, but they are associated with incompleteness of data, which could affect the results.

\section{Contribution Statement}

$\mathrm{KO}$ conceived of the idea for the study and performed the statistical analysis. KO and PB designed the analysis, conducted the data interpretation and wrote the manuscript. KO, PB, AKC, AT, RK, MG, MP, AW and MM researched the data. KJF and GO reviewed the manuscript. MGCL and APM designed and coordinated the registries. JD coordinated the registry nationwide. All authors edited and approved the final version of the manuscript.

\section{Funding}

The study is financed from the statutory funds of the European Society of Cardiology (ESC). 


\section{Compliance with Ethical Standards}

\section{Conflict of Interest}

The authors declare that they have no conflict of interest.

\section{Ethical Approval}

This article does not contain any studies with animals performed by any of the authors. All procedures performed in studies involving human participants were in accordance with the ethical standards of the institutional and/or national research committee and with the 1964 Helsinki Declaration and its later amendments or comparable ethical standards.

\section{Informed Consent}

Informed consent was obtained from all individual participants included in the study.

\section{Publisher's Note}

Springer Nature remains neutral with regard to jurisdictional claims in published maps and institutional affiliations.

\section{References}

1. Ponikowski P, Voors AA, Anker SD, Bueno H, Cleland JG, Coats AJ, et al. 2016 ESC guidelines for the diagnosis and treatment of acute and chronic heart failure: the Task Force for the Diagnosis and Treatment of Acute and Chronic Heart Failure of the European Society of Cardiology (ESC) developed with the special contribution of the Heart Failure Association (HFA) of the ESC. Eur Heart J. 2016;37:2129-200.

2. Mueller TM, Vuckovic KM, Knox DA, Williams RE. Telemanagement of heart failure: a diuretic treatment algorithm for advanced practice nurses. Heart Lung. 2002;31:340-7.

3. Komajda M, Anker SD, Cowie MR, Filippatos GS, Mengelle B, Ponikowski P, et al. Physicians' adherence to guideline-recommended medications in heart failure with reduced ejection fraction: data from the QUALIFY global survey. Eur J Heart Fail. 2016;18:514-22

4. Maggioni AP, Anker SD, Dahlstrom U, Filippatos G, Ponikowski P, Zannad F, et al. Are hospitalized or ambulatory patients with heart failure treated in accordance with European Society of Cardiology guidelines? Evidence from 12,440 patients of the ESC Heart Failure Long-Term Registry. Eur J Heart Fail. 2013;15:1173-84.

5. Domanski M, Norman J, Pitt B, Haigney M, Hanlon S, Peyster E, et al. Diuretic use, progressive heart failure, and death in patients in the Studies Of Left Ventricular Dysfunction (SOLVD). J Am Coll Cardiol. 2003;42:705-8.

6. Cosin J, Diez J, investigators T. Torasemide in chronic heart failure: results of the TORIC study. Eur J Heart Fail. 2002;4:507-13.

7. Murray MD, Deer MM, Ferguson JA, Dexter PR, Bennett SJ, Perkins SM, et al. Open-label randomized trial of torsemide compared with furosemide therapy for patients with heart failure. Am J Med. 2001;111:513-20.

8. Fortuno A, Muniz P, Ravassa S, Rodriguez JA, Fortuno MA, Zalba G, et al. Torasemide inhibits angiotensin II-induced vasoconstriction and intracellular calcium increase in the aorta of spontaneously hypertensive rats. Hypertension. 1999;34:138-43.

9. Harada K, Izawa H, Nishizawa T, Hirashiki A, Murase Y, Kobayashi M, et al. Beneficial effects of torasemide on systolic wall stress and sympathetic nervous activity in asymptomatic or mildly symptomatic patients with heart failure: comparison with azosemide. J Cardiovasc Pharmacol. 2009;53:468-73.

10. Lopez B, Querejeta R, Gonzalez A, Sanchez E, Larman M, Diez J. Effects of loop diuretics on myocardial fibrosis and collagen type I turnover in chronic heart failure. J Am Coll Cardiol. 2004;43:2028-35. 
11. Balsam P, Tyminska A, Kaplon-Cieslicka A, Ozieranski K, Peller M, Galas M, et al. Predictors of one-year outcome in patients hospitalised for heart failure: results from the Polish part of the Heart Failure Pilot Survey of the European Society of Cardiology. Kardiol Pol. 2016;74:9-17.

12. Kaplon-Cieslicka A, Tyminska A, Peller M, Balsam P, Ozieranski K, Galas M, et al. Diagnosis, clinical course, and 1-year outcome in patients hospitalized for heart failure with preserved ejection fraction (from the Polish cohort of the European Society of Cardiology Heart Failure Long-Term Registry). Am J Cardiol. 2016;118:535-42.

13. Eshaghian S, Horwich TB, Fonarow GC. Relation of loop diuretic dose to mortality in advanced heart failure. Am J Cardiol. 2006;97:1759-64.

14. D'Agostino RB Jr. Propensity score methods for bias reduction in the comparison of a treatment to a non-randomized control group. Stat Med. 1998;17:2265-81. 15.

15. Austin PC, Jembere N, Chiu M. Propensity score matching and complex surveys. Stat Methods Med Res. 2018;27:1240-57.

16. Mentz RJ, Hasselblad V, DeVore AD, Metra M, Voors AA, Armstrong PW, et al. Torsemide versus furosemide in patients with acute heart failure (from the ASCEND-HF trial). Am J Cardiol. 2016;117:404-11.

17. Muller K, Gamba G, Jaquet F, Hess B. Torasemide vs. furosemide in primary care patients with chronic heart failure NYHA II to IV — efficacy and quality of life. Eur J Heart Fail. 2003;5:793801.

18. Anand IS, Kalra GS, Harris P, Poole-Wilson PA, Panzali A, De Giuli F, et al. Diuretics as initial and sole treatment in chronic cardiac failure. Cardioscience. 1991;2:273-8.

19. Packer M. The neurohormonal hypothesis: a theory to explain the mechanism of disease progression in heart failure. J Am Coll Cardiol. 1992;20:248-54.

20. Swedberg K, Eneroth P, Kjekshus J, Wilhelmsen L. Hormones regulating cardiovascular function in patients with severe congestive heart failure and their relation to mortality. CONSENSUS Trial Study Group. Circulation. 1990;82:1730-6.

21. Brater DC. Benefits and risks of torasemide in congestive heart failure and essential hypertension. Drug Saf. 1996;14:104-20.

22. Han LN, Guo SL, Lin XM, Shi XM, Zang CB, Yang LM, et al. Torasemide reduces dilated cardiomyopathy, complication of arrhythmia, and progression to heart failure. Genet Mol Res. 2014;13:7262-74.

23. Dini FL, Ghio S, Klersy C, Rossi A, Simioniuc A, Scelsi L, et al. Effects on survival of loop diuretic dosing in ambulatory patients with chronic heart failure using a propensity score analysis. Int J Clin Pract. 2013;67:656-64

24. Ozierański K, Kapłon-Cieślicka A, Balsam P, Tymińska A, Wancerz A, Peller M, et al. Do $\beta$ blockers improve one-year survival in heart failure patients with atrial fibrillation? Results from the ESC-HF Registry. Pol Arch Intern Med. 2018.

25. Yilmaz MB, Gayat E, Salem R, Lassus J, Nikolaou M, Laribi S, et al. Impact of diuretic dosing on mortality in acute heart failure using a propensity-matched analysis. Eur J Heart Fail. 2011;13:1244-52.

26. Vargo DL, Kramer WG, Black PK, Smith WB, Serpas T, Brater DC. Bioavailability, pharmacokinetics, and pharmacodynamics of torsemide and furosemide in patients with congestive heart failure. Clin Pharmacol Ther. 1995;57:601-9.

27. Ballester MR, Roig E, Gich I, Puntes M, Delgadillo J, Santos B, et al. Randomized, open-label, blinded-endpoint, crossover, single-dose study to compare the pharmacodynamics of torasemide-PR $10 \mathrm{mg}$, torasemide-IR $10 \mathrm{mg}$, and furosemide-IR $40 \mathrm{mg}$, in patients with chronic heart failure. Drug Des Devel Ther. 2015;9:4291-302.

28. Kido H, Ohtaki Y. Torasemide (LUPRAC): a review of its pharmacological and clinical profile. Nihon Yakurigaku Zasshi. 2001;118:97-105.

29. Mentz RJ, Stevens SR, DeVore AD, Lala A, Vader JM, Abouezzeddine OF, et al. Decongestion strategies and renin-angiotensin-aldosterone system activation in acute heart failure. JACC Heart Fail. 2015;3:97-107.

30. Balsam P, Ozierański K, Tymińska A, Główczyńska R, Peller M, Fojt A, et al. The impact of torasemide on haemodynamic and neurohormonal stress, and cardiac remodelling in heart failure-TORNADO: a study protocol for a randomized controlled trial. Trials. 2017;18(1):36

31. Mamcarz A, Filipiak KJ, Drozdz J, Nessler J, Tykarski A, Niemczyk M, et al. Loop diuretics: old and new ones-which one to choose in clinical practice? Experts' group consensus endorsed by the Polish Cardiac Society Working Group on Cardiovascular Pharmacotherapy and Working Group on Heart Failure. Kardiol Pol. 2015;73:225-32.

32. Buggey J, Mentz RJ, Pitt B, Eisenstein EL, Anstrom KJ, Velazquez EJ, et al. A reappraisal of loop diuretic choice in heart failure patients. Am Heart J. 2015;169:323-33. 